\title{
COMPARAÇÃO DOS RESULTADOS DA CLASSIFICAÇÃO SUPERVISIONADA DA COBERTURA DO SOLO POR MÁXIMA VEROSSIMILHANÇA DE IMAGENS LANDSAT-5 TM E ALOS AVNIR-2
}

\section{COMPARISON OF RESULTS OF THE SUPERVISED CLASSIFICATION OF SOIL COVERAGE BY MAXIMUM LIKELIHOOD OF IMAGES LANDSAT-5 TM AND ALOS AVNIR-2}

\author{
Orjana Silva ${ }^{1}$, Francisco Dourado ${ }^{1}$ \\ ${ }^{1}$ Universidade do Estado do Rio de Janeiro (UERJ), Rio de Janeiro, RJ, Brasil
}

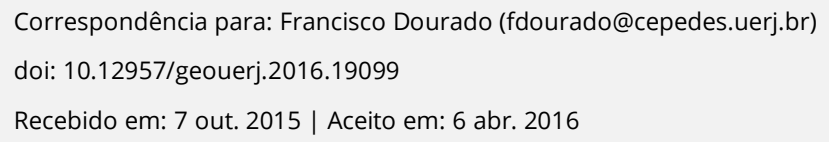

\section{RESUMO}

As transformações na cobertura da terra, principalmente na região dos trópicos, vem ocorrendo de forma acelerada e com isso a maior e a mais diversa floresta tropical do mundo, a Floresta Amazônica ou Bioma Amazônia, também sofre com esse processo. No presente estudo comparou-se os resultados obtidos da caracterização da cobertura do solo através da classificação supervisionada por máxima verossimilhança de imagens LANDSAT 5 TM e ALOS AVNIR-2. A área de estudo escolhida para a avaliação foi a área do Projeto de Assentamento Conjunto de Carlinda que se localiza no Município de Carlinda, inserido na denominada Amazônia Legal. Nos resultados foi observado que as áreas das classes nas duas diferentes imagens, apresentam valores muito próximos. As variações apresentadas devem-se devido à diferença entre as resoluções espaciais das imagens e a diferença das regiões espectrais das bandas envolvidas nas análises, em especial a banda Verde. Analisando as classes quanto à representatividade espacial, em ambas as imagens, a menos representada foi a classe envolvendo os corpos d'água, seguida da classe de vegetação preservada e vegetação de áreas úmidas. $\mathrm{A}$ classe de vegetação antropizada/solo exposto foi a classe mais representada em ambas as classificações. Em relação a área de trabalho, observou-se que na região há a predominância de áreas utilizadas em diversas atividades antrópicas e escassez de áreas com vegetação preservada. Esse fato é diametralmente oposto ao que se esperaria de uma área situada na Amazônia Legal, onde, pela legislação vigente deveria apresentar $80 \%$ de seu território com vegetação preservada.

Palavras-chave: Sensoriamento remoto; LANDSAT; ALOS; Classificação; Uso do solo; Classificação supervisionada; Máxima verossimilhança.

\section{ABSTRACT}

Changes in land cover, especially in the tropics, has been occurring at an accelerated rate and with it the largest and most diverse rainforest in the world, the Amazon jungle or the Amazon Biome, also suffers from this process. At present study were compared results obtained from characterization of land cover by supervised classification by maximum likelihood using LANDSAT 5 TM and ALOS-2 AVNIR images. The study area chosen for this evaluation was the area of the Settlement Project Carlinda in Mato Grosso State, located on the so-called Legal Amazon. From the results it was observed that areas of each classes in the two images have similar values. The small variations should be presented due to the difference between the spatial resolutions of the images and the difference of the spectral bands regions involved in the analysis, especially the Green band. Analyzing the classes according spatial representation, in both images, the water bodies class was the smaller, followed by preserved vegetation class and wetland vegetation class. The class of anthropic vegetation / exposed soil was the most represented class in both classifications. Regarding the study area, it was observed that in the region there is a predominance of areas used in various human activities and gradual reduction of areas with preserved vegetation. This fact is diametrically opposite to what one would expect from an area in the Amazon, where, by the law need $80 \%$ of its territory be preserved.

Keywords: Remote sensing; LANDSAT; ALOS; classification; Land Use; Supervised classification; Maximum likelihood. 


\section{INTRODUÇÃO}

As transformações na cobertura do solo, principalmente na região dos trópicos, vem ocorrendo de forma acelerada. Nas últimas duas décadas, porções significativas das florestas tropicais, inclusive da Floresta Amazônica, foram desmatadas como resultado da expansão das fronteiras agrícolas (CORREIA et al., 2005).

Até a década de 1960, a ocupação humana teve pouca influência no domínio da Floresta Amazônica. Mas a partir dos anos de 1970, sua ocupação tornou-se prioridade nacional com o Plano de Integração Nacional (PIN) para integrar o território amazônico ao resto do país. Assim, o Governo Federal passou a subsidiar a ocupação de terras para expansão pioneira, iniciando um processo de intensas e significativas alterações ambientais até os dias atuais (ALMEIDA et al., 2010; SKOLE et al., 1994).

Um exemplo disso é a ocupação do norte do Estado do Mato Grosso que se iniciou com a abertura da BR 163 inaugurada em 1974 e onde os primeiros empreendimentos foram realizados por empresas privadas de colonização que implantaram projetos de milhares de hectares (ha) e de onde surgiram cidades como Alta Floresta, Colíder ou Sinop (CASTRO et al., 2002).

Dados do Projeto de Monitoramento da Floresta Amazônica Brasileira por Satélite - PRODES mostram que já há alguns anos, o Mato Grosso alcança regularmente os maiores valores de superfície empregada na agricultura (INPE, 2008). Porém a essência do desmatamento no Estado está ligada a extensão de áreas de pastagem (FEARNSIDE, 2001).

Atualmente, grande parte do trabalho de monitoramento e estimativa do desmatamento e mapeamento do uso do solo na Amazônia brasileira é feito a partir de dados dos satélites das famílias LANDSAT ou CBERS (ALVES et al., 1996). A utilização dessas ferramentas vem obtendo resultados satisfatórios por sua precisão, agilidade na coleta dos dados e custo inferior quando comparado aos métodos convencionais (SÁ et al., 2008; ROSA, 2003; SOUZA e MATRICARDI, 2011). A 
evolução do sensoriamento remoto vem sendo marcada por sensores cada vez mais confiáveis e temáticos (FERREIRA et al., 2008) e o desenvolvimento de sensores com alta resolução espacial vem permitindo aos usuários o mapeamento cada vez mais detalhado da superfície terrestre (PONZONI e REZENDE, 2004). Além dos sensores tradicionalmente conhecidos como o LANDSAT e o SPOT, o número de novos sensores orbitais disponíveis tem crescido muito com o passar dos anos (e.g. ALOS AVNIR-2 e CBERS), assim como o custo de acesso aos dados tem reduzido.

O presente estudo tem por objetivo comparar os resultados obtidos através da classificação supervisionada por máxima verossimilhança de imagens LANDSAT 5 TM+ e ALOS AVNIR-2 na avaliação da caracterização da cobertura do solo em um assentamento do INCRA no município de Carlinda, na região extremo Norte do Estado de Mato Grosso.

\section{ÁREA DE ESTUDO}

A área de estudo engloba o Projeto de Assentamento Conjunto de Carlinda (PAC Carlinda) e encontra-se inserida no Município de Carlinda e parte de Alta Floresta no extremo norte do Estado do Mato Grosso, região Centro-Oeste do Brasil (Figura 1).

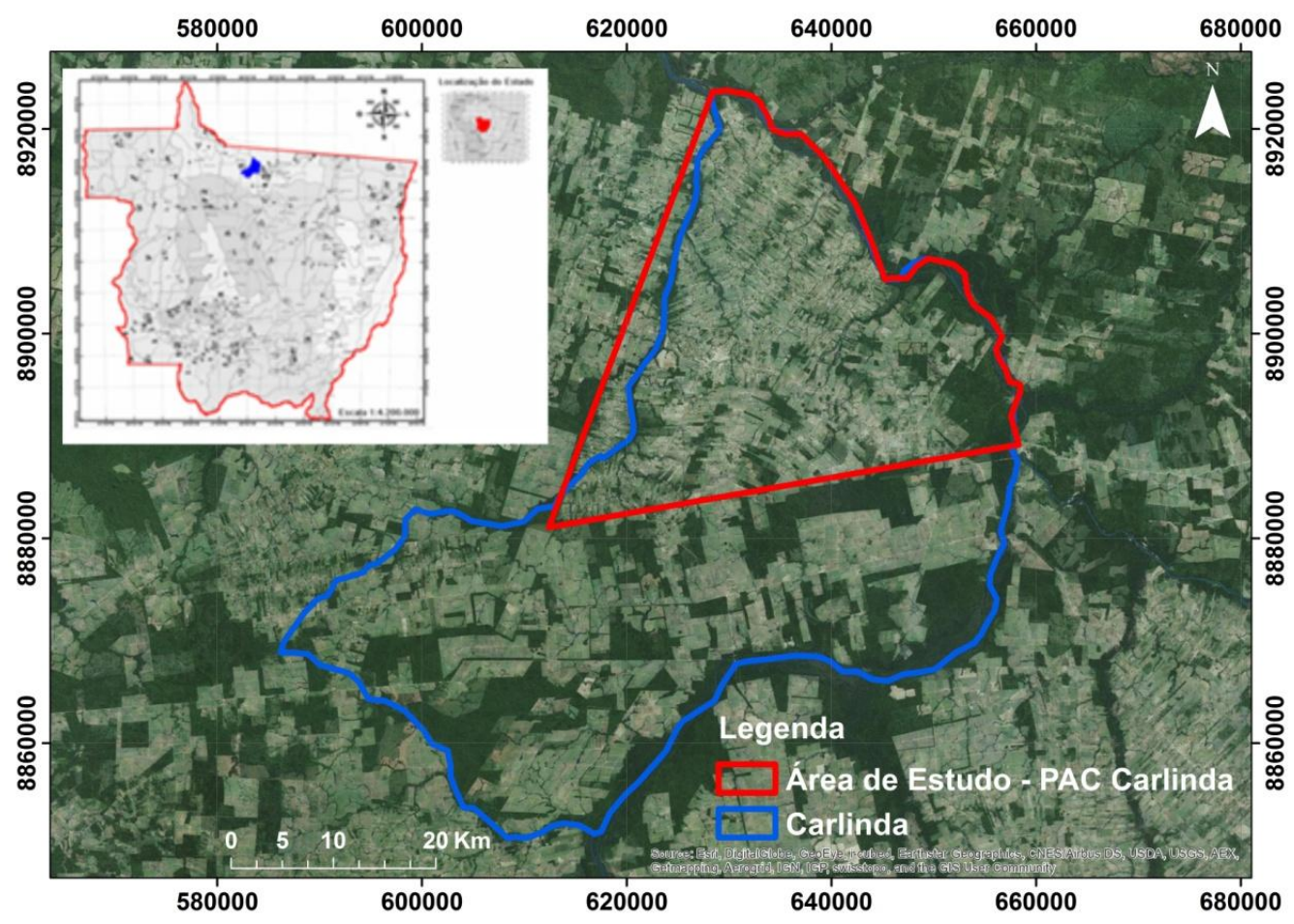

Figura 1. Limites do município de Carlinda e da área de estudo (circundada em vermelho). 
Carlinda é um município localizado no norte de Mato Grosso, a $750 \mathrm{~km}$ da capital Cuiabá. Com uma área total de $2.393,024 \mathrm{~km}^{2}$ e população de 10.990 habitantes (IBGE, 2010). Em fevereiro de 1981 surgiu o Projeto de Assentamento Conjunto (PAC) Carlinda, com 96.000 hectares, associado ao Instituto Nacional de Colonização e Reforma Agrária (INCRA) e a iniciativa privada (p.ex. cooperativas como a Cooperativa Agrícola da Cotia - Cooperativa Central/CACCC) (CASTRO et al., 2002).

A área estudada totaliza 1.072,31 km2 englobando uma área um pouco maior que a área do PAC Carlinda. Segundo Ferreira et al. (2013), através de interpretação de imagem de satélite LANDSAT 2 sensor MSS de 29/07/1980, o desmatamento ocorrido até 1980 se deu principalmente pela abertura de estradas. Após 1980, com o processo de ocupação do município de Carlinda, o processo de desmatamento ocorreu devido às atividades madeireira e pecuária, sendo a última a maior contribuinte. Na década de 1990, ocorreu a abertura de estradas internas, criadas pelos próprios pecuaristas para baratear os custos de transportes.

Segundo Ferreira et al. (2013), por se encontrar incluso na denominada Amazônia Legal, 80\% de sua vegetação deveria se manter preservada, porém apresentou mais de $70 \%$ de sua área desmatada. Até 0 ano de 1990 , foram desmatados aproximadamente 62.000 ha (28,75\% de sua área total), mostrando que Carlinda, já estava desmatada 8,75\% acima do permitido no código florestal vigente na época (lei n. ${ }^{0} 4.771$ de 1965) (FERREIRA et al., 2013). O autor, baseando-se em imagens de 2011, calculou que o município apresentava 20,44\% de área de floresta preservada e 79,66\% desmatada, exatamente o inverso do que a lei permite. Segundo o autor, o município encontrava-se em situação critica com um índice alto de degradação atingindo áreas de preservação permanente e nascentes.

\section{MATERIAIS E MÉTODOS}

Neste trabalho foram utilizadas uma imagem ALOS AVNIR-2, com resolução espacial de 10 metros, cedida pela Agência de Exploração Aeroespacial do Japão (JAXA) de 29 de Junho de 2009 com um nível de processamento de 1B2 já corrigida radiometricamente e geometricamente, e uma imagem 
LANDSAT 5 TM, com resolução espacial de 30 metros, de 26 de Junho de 2009 adquirida no repositório de imagens do Instituto Nacional de Pesquisas Espaciais/INPE (http://www.dgi.inpe.br/CDSR/). O Datum utilizado foi o WGS84 e a projeção UTM 21S.

As imagens foram processadas no programa ENVI 4.7. Primeiramente, a imagem LANDSAT TM foi georreferenciada usando-se como referência a imagem ALOS AVNIR-2. O segundo passo foi identificar classes de cobertura do solo que possuíssem diferenças espectrais entre si e posteriormente adaptá-las em função das classes utilizadas por BOULOGNE (2011) para futuras comparações entre os estudos realizados. As classes de cobertura do solo identificadas foram: corpos d'água, vegetação preservada, vegetação preservada de área úmida e vegetação antropizada/solo exposto (Quadro 1).

\begin{tabular}{|c|c|}
\hline Classe & Características \\
\hline corpos d'água & $\begin{array}{l}\text { Quaisquer corpos d’água como rios, riachos, lagos, } \\
\text { açudes e barragens }\end{array}$ \\
\hline vegetação preservada & $\begin{array}{l}\text { Áreas de vegetação totalmente preservada e sem } \\
\text { intervenções antrópicas excetuando matas ciliares }\end{array}$ \\
\hline vegetação preservada de área úmida & $\begin{array}{c}\text { Áreas com vegetação totalmente preservada em } \\
\text { solo úmido, mata ciliar totalmente preservada e } \\
\text { sem intervenções antrópicas, áreas com mata } \\
\text { bordejando lagos, açudes e barragens de maior } \\
\text { dimensão }\end{array}$ \\
\hline vegetação antropizada/solo exposto & $\begin{array}{l}\text { Áreas desmatadas, áreas com vegetação } \\
\text { antropizada, áreas com vegetação em recuperação, } \\
\text { solo exposto, áreas urbanas e agropecuárias }\end{array}$ \\
\hline
\end{tabular}

Quadro 1. Caracterização das classes de cobertura do solo identificadas.

A partir da discretização dessas classes de cobertura do solo, foram selecionadas 10 amostras de referência (áreas nas imagens) para cada classe de interesse que fossem espacialmente comuns nas duas imagens, ou seja, que estivessem localizadas nos mesmos lugares em ambas. Essas amostras 
foram selecionadas, buscando representar a variabilidade de cada classe e caracterizar áreas homogêneas.

Também no programa ENVI 4.7. Foram executadas as classificações supervisionadas por máxima verossimilhança, utilizando as amostras de regiões de interesse como base para a busca de pixels e regiões semelhantes pelo classificador automático, utilizando as bandas do visível (azul, verde e vermelho) e infravermelho próximo de ambas as imagens (Tabela 1).

\begin{tabular}{ccccc}
\hline Sensor & \multicolumn{4}{c}{ Regiões espectrais das bandas } \\
\cline { 2 - 5 } & Azul & Verde & Vermelho & IV-Próximo \\
ALOS AVNIR-2 & $420-500$ & $520-660$ & $610-690$ & $760-890$ \\
LANDSAT 5 TM & $450-520$ & $520-600$ & $630-690$ & $760-900$ \\
\hline
\end{tabular}

Tabela 1. Correspondência as bandas espectrais envolvidas nas análises.

No programa ArcGIS 10.0, as imagens resultantes da classificação foram convertidas em vetores, onde foi calculada a área de cada polígono. Cada um dos dois arquivos com os resultados teve sua tabela exportada em formato texto com informações de todos os polígonos gerados e suas respectivas áreas dentro da área de estudo. As tabelas em formato texto foram importadas para o programa Excel/Office/Microsoft onde foram calculados o número de polígonos gerados e a área total de cada classe. Os mapas finais foram produzidos também no programa ArcGIS 10.0.

\section{RESULTADOS E DISCUSSÕES}

Foram gerados pelo método de classificação supervisionada por Máxima Verossimilhança, dois mapas de caracterização do solo referentes as Imagens ALOS AVNIR-2 e LANDSAT5 TM (Figuras 2 e 3 respectivamente). 


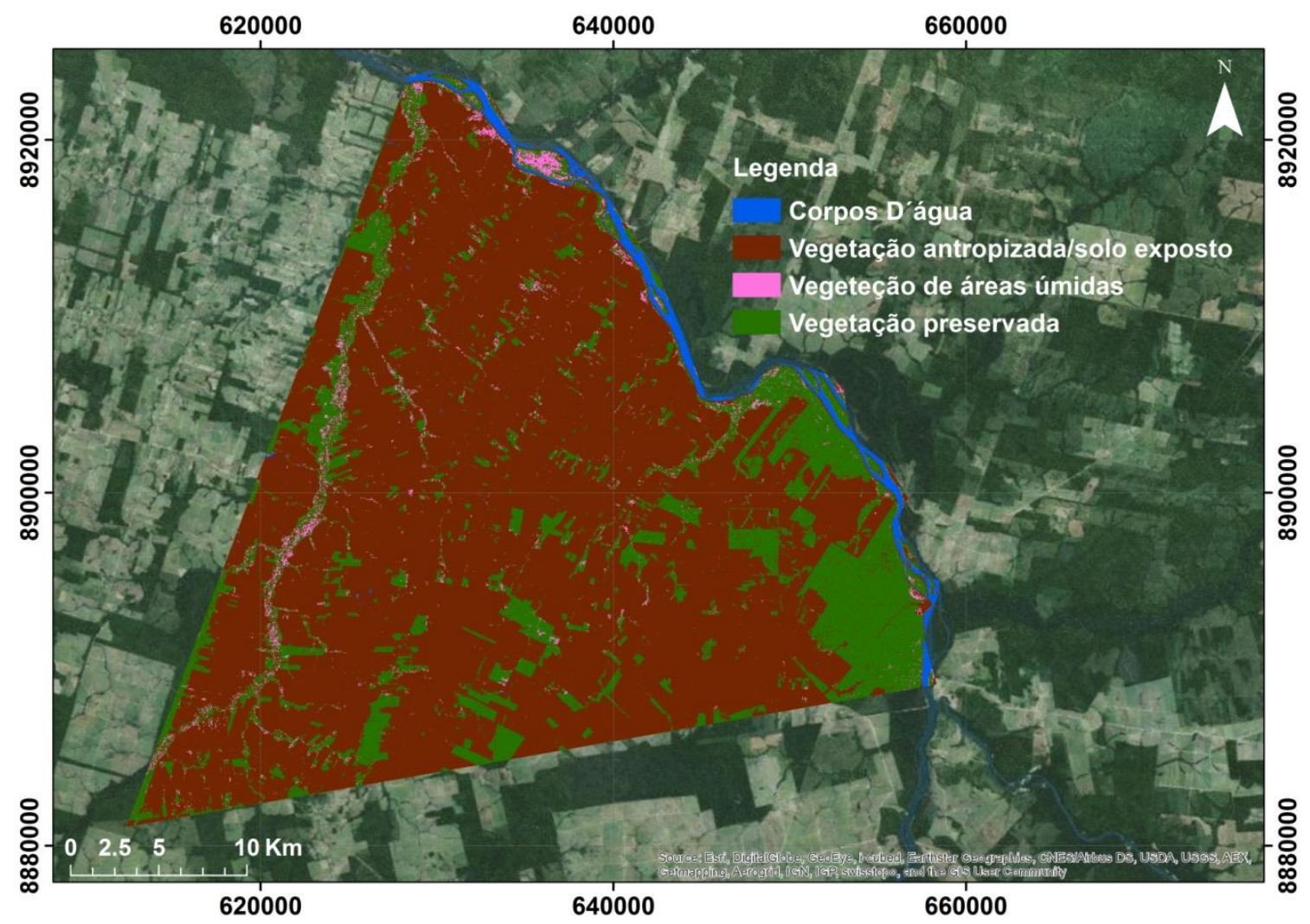

Figura 2. Classificação da cobertura do solo a partir da Imagem ALOS AVNIR-2 pelo método de classificação por Máxima Verossimilhança.

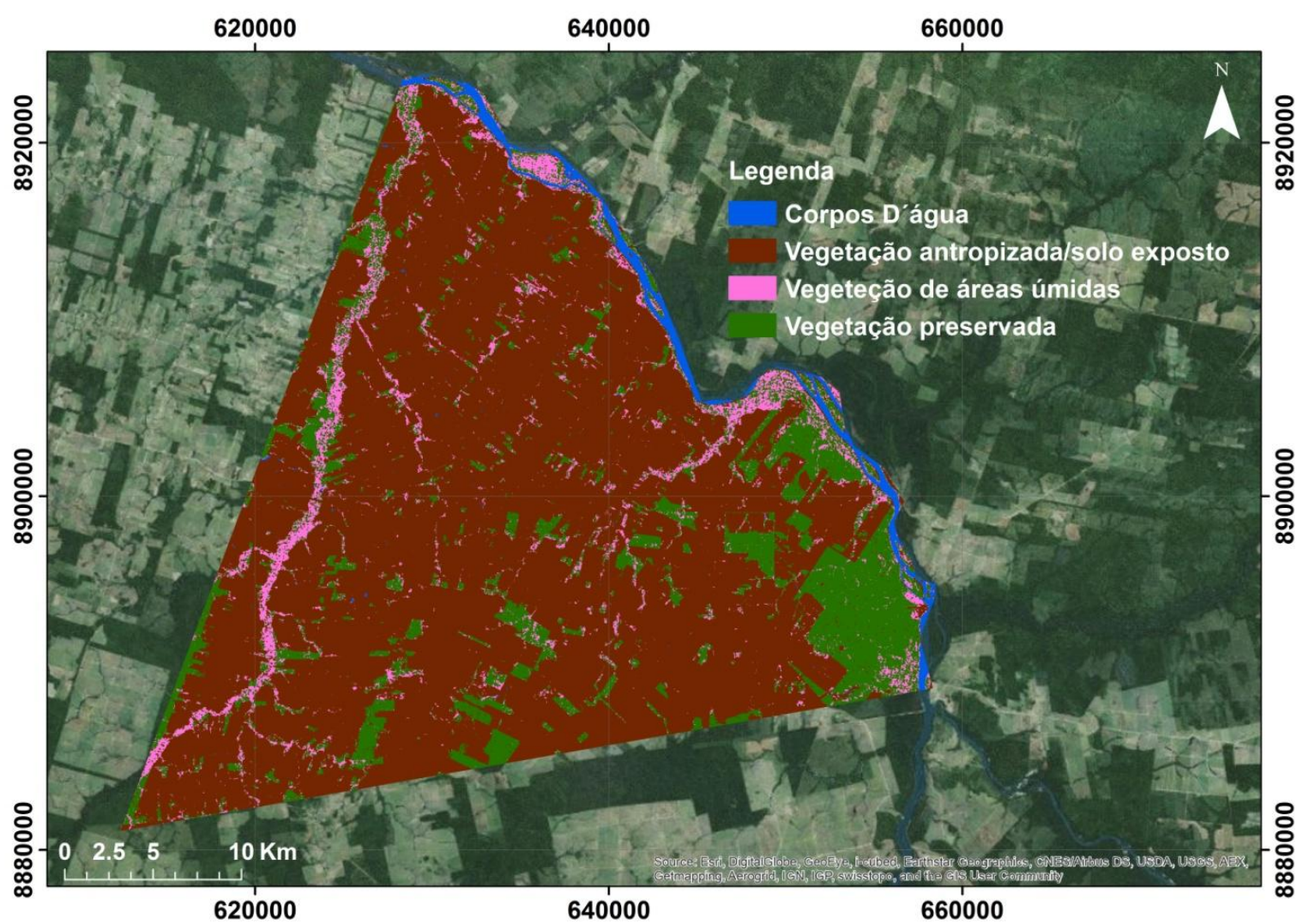

Figura 3. Classificação da cobertura do solo a partir da Imagem LANDSAT5 TM pelo método de classificação por Máxima Verossimilhança. 
Analisando a Tabela 1 observa-se que a classificação da imagem ALOS AVNIR 2 em todas as classes gerou um maior número de polígonos em comparação com a imagem LANDSAT 5 TM. Isso ocorreu devido a melhor resolução espacial que possibilita uma melhor discriminação entre as classes. A quantidade de polígonos gerados para cada classe varia para as duas imagens analisadas, assim como as áreas que eles ocupam. Nas duas imagens, a maior quantidade de polígonos foi gerada para a classe de vegetação de áreas úmidas, seguida da classe de vegetação preservada, vegetação antropizada/solo exposto e por último para a classe de corpos d’água. Com exceção da classe de vegetação antropizada/solo exposto que para a imagem LANDSAT 5 TM a classificação só gerou um único polígono.

Em termos de área calculada, as 4 (quatro) classes seguiram o mesmo padrão em ambas imagens analisadas. A classe menos representativa foi a classe Corpos d'água (rios, lagos, açudes...). A classe de vegetação preservada é a segunda menor em termos de representatividade, seguida da vegetação de áreas úmidas. A classe mais representativa é a classe de vegetação antropizada/solo exposto.

ALOS AVNIR 2 LANDSAT 5 TM

\begin{tabular}{|c|c|c|c|c|c|}
\hline Classes & $\begin{array}{l}\text { Num. de } \\
\text { polígonos }\end{array}$ & Área em $\mathbf{k m}^{2}$ & $\begin{array}{l}\text { Num. de } \\
\text { polígonos }\end{array}$ & $\begin{array}{c}\text { Área em } \\
\text { km }^{2}\end{array}$ & $\begin{array}{c}\text { Variação } \\
\text { da área }\end{array}$ \\
\hline
\end{tabular}

\begin{tabular}{|c|c|c|c|c|c|}
\hline Corpos d’água & $\begin{array}{c}2.546 \\
(2,23 \%)\end{array}$ & $23,40(2,18 \%)$ & $\begin{array}{c}1.377 \\
(7,37 \%)\end{array}$ & $\begin{array}{c}25,70 \\
(2,40 \%)\end{array}$ & $15,52 \%$ \\
\hline Veg. áreas úmidas & $\begin{array}{c}63.236 \\
(55,49 \%)\end{array}$ & $160,92(15,01 \%)$ & $\begin{array}{c}10.345 \\
(55,33 \%)\end{array}$ & $\begin{array}{c}156,46 \\
(15,59 \%)\end{array}$ & $-2,85 \%$ \\
\hline Vegetação preservada & $\begin{array}{c}39.097 \\
(34,31 \%)\end{array}$ & $143,95(13,42 \%)$ & $\begin{array}{c}6.973 \\
(37,30 \%)\end{array}$ & $\begin{array}{c}126,06 \\
(11,76 \%)\end{array}$ & $-14,19 \%$ \\
\hline Veg. antropizada & $\begin{array}{c}9.088 \\
(7,97 \%)\end{array}$ & $744,04(69,39 \%)$ & $\begin{array}{c}1 \\
(1,01 \%)\end{array}$ & $\begin{array}{c}764,09 \\
(71,26 \%)\end{array}$ & $2,62 \%$ \\
\hline
\end{tabular}

Vegetação antropizada/solo exposto

Tabela 2. Número de polígonos e áreas a partir da classificação por Máxima Verossimilhança de imagens ALOS 
Para a classe de Vegetação antropizada/solo exposto observou-se que a representatividade das áreas em termos de número de polígonos gerados segue um padrão onde quanto menor a área média dos polígonos, maior o número de polígonos gerados. Houve um decréscimo a medida que a área dos polígonos envolvidos aumentou (Figura 4). Exceto por um aumento no número de polígonos entre 7.201m2 e 8.100m2 da imagem ALOS AVNIR 2. É interessante destacar que esta classe apresentou um comportamento completamente diverso das demais classes quando da classificação da imagem LANDSAT 5 TM: nesse caso, o resultado apenas um único polígono com área de 764,09 km2. Novamente atribui-se à resolução espacial da imagem esse resultado.

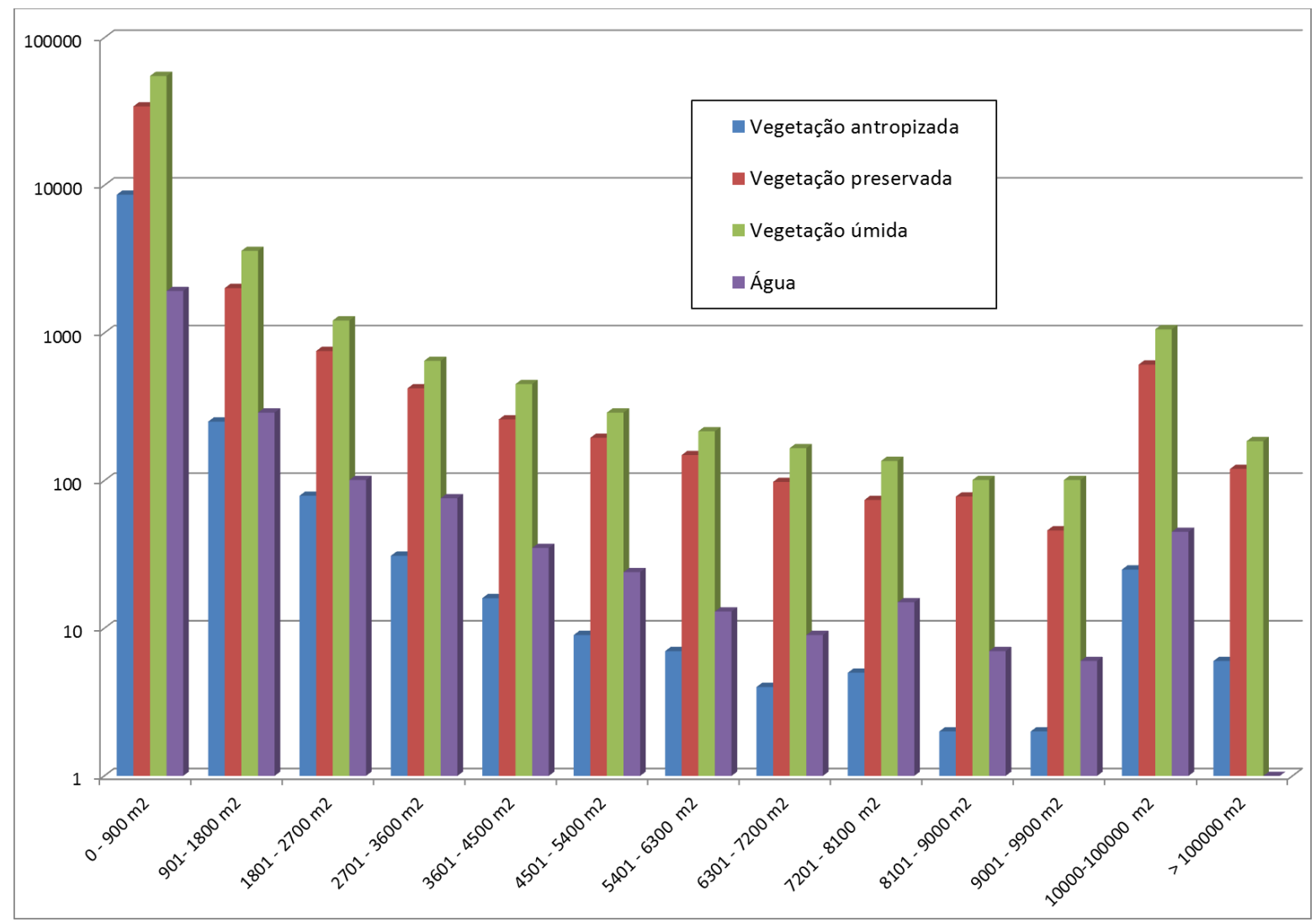

Figura 4. Classificação da cobertura do solo a partir da Imagem LANDSAT5 TM pelo método de classificação por Máxima Verossimilhança.

Em ambas classificações é possível observar que a área de estudo se encontra intensamente antropizada. Na classificação da imagem ALOS 69,39\% da área se apresenta antropizada, enquanto na classificação usando a imagem LANDSAT esse percentual sobe para 71,26\% (Tabela 2). 
Vegetação Preservada

Para a classe de Vegetação Preservada observou-se que a representatividade das áreas em termos de número de polígonos gerados segue o padrão de que quanto menor a área dos mesmos maior o número de polígonos gerados. Houve um decréscimo a medida que a área dos polígonos envolvidos aumentou. Exceto por um aumento no número de polígonos entre $8.101 \mathrm{~m} 2$ e $9.000 \mathrm{~m} 2$ da imagem ALOS AVNIR 2, voltando a cair e só tendo um acréscimo no intervalo de área entre $10.000 \mathrm{~m} 2$ e $100.000 \mathrm{~m} 2$ em relação ao intervalo de área anterior, voltando a cair para polígonos maiores que 100.000m2 (Figura $4)$.

De maneira oposta à classe Vegetação antropizada/solo exposto, a classe Vegetação preservada, apresentou uma variação entre as áreas calculadas alta entre as diferentes imagens (14,19\%). A grande diferença entre as áreas calculadas está associada ao comportamento espectral das folhas devido à clorofila e a água em sua estrutura que estão registrados mais enfaticamente na banda espectral Verde. Essa banda ocupa faixas diferentes regiões no espectro eletromagnético para cada sensor (ALOS x LANDSAT). Como pode ser observado na Tabela 1 há uma diferença de 60 nm entre elas.

Corpos d'água

Para a classe de corpos d'água observou-se que a representatividade das áreas em termos de número de polígonos gerados é maior quanto menor a área. Houve um decréscimo a medida que a área dos polígonos envolvidos aumenta. Exceto por um aumento, em relação ao intervalo de área anterior, no número de polígonos da imagem LANDSAT 5 TM no intervalo de área entre $4.501 \mathrm{~m} 2$ e $5.400 \mathrm{~m} 2 \mathrm{e}$ na imagem ALOS AVNIR 2 entre $7201 \mathrm{~m} 2$ e $8.100 \mathrm{~m} 2$, voltando a cair progressivamente. Apresentando um novo aumento entre $10.000 \mathrm{~m} 2$ e $100.000 \mathrm{~m} 2$ e voltando a cair para polígonos maiores que 100.000m2 (Figura 4).

Vegetação de áreas úmidas 
Para a classe de Vegetação de áreas úmidas observou-se que a representatividade das áreas em termos de número de polígonos gerados segue o padrão anterior, de que quanto menor a área dos mesmos maior o número de polígonos gerados. Houve um decréscimo a medida que a área dos polígonos envolvidos aumentou. Exceto por um aumento entre $10.000 \mathrm{~m} 2$ e $100.000 \mathrm{~m} 2$ em ambas as imagens analisadas, voltando a cair para polígonos maiores que 100.000m2 (Figura 4).

Tomando uma pequena região, em detalhe, da área de estudo, ao compararmos o resultado da classificação com a composição colorida RGB 321 de cada imagem com a classificação correspondente da cada sensor, se nota uma alta correspondência das classes como pode ser observado na imagem de satélite (Figura 5).
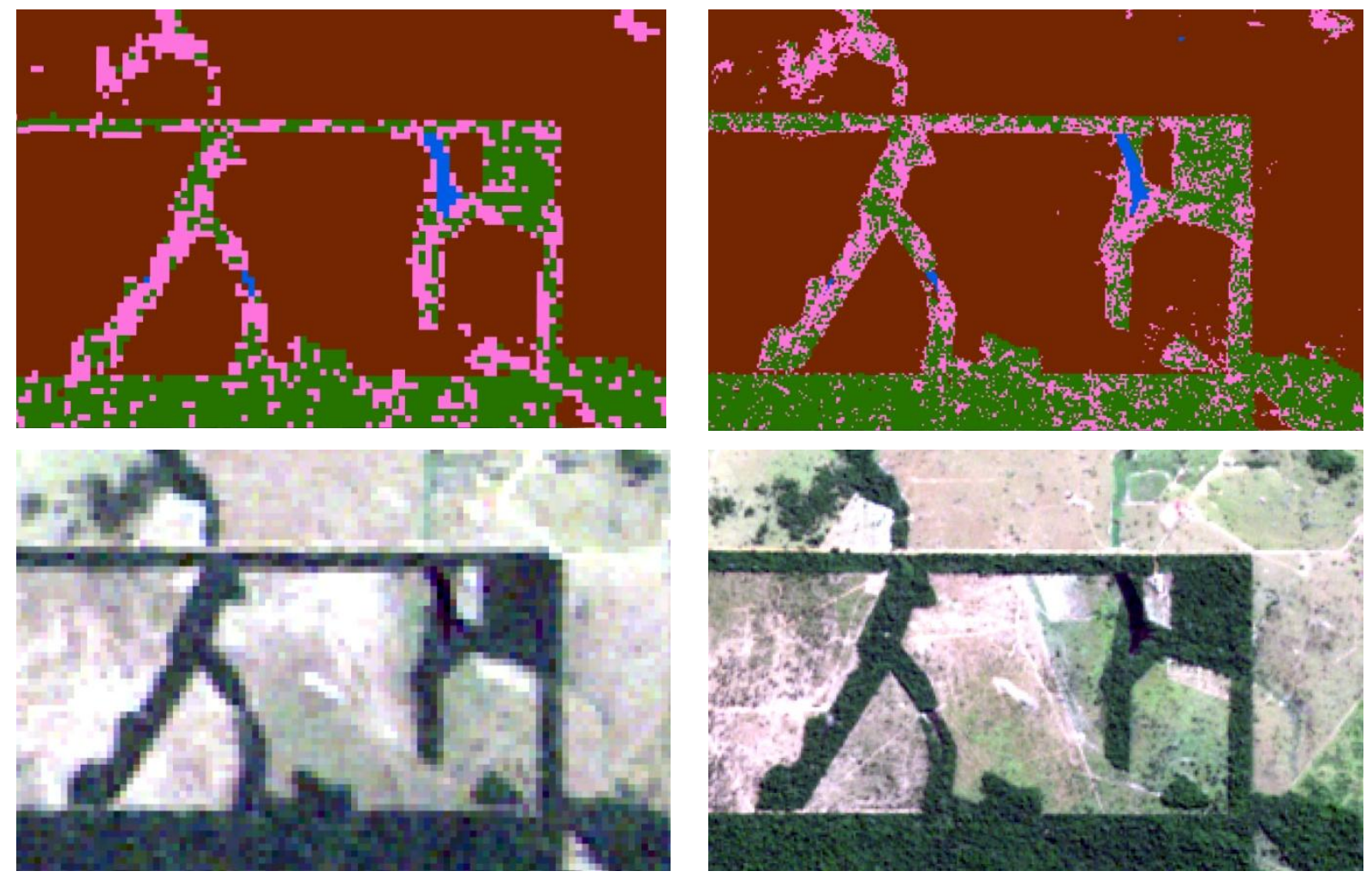

Figura 5. Resultado da classificação por Máxima Verossimilhança e composição colorida RGB 321 das imagens analisadas.(a) Classificação da imagem Landsat 5 TM (b) Classificação da imagem ALOS AVNIR-2 (c)

Composição 321 Landsat 5 TM (d) Composição 321 ALOS AVNIR-2. Legenda: Azul - corpos d'água, Marrom - vegetação antropizada/solo exposto, Rosa - vegetação de áreas úmidas e Verde - vegetação preservada. 


\section{CONSIDERAÇÕES FINAIS}

Baseado nos resultados (Figura 2 e Figura 3), observamos que as áreas e percentuais calculados para cada classe, nas duas diferentes imagens, apresentam valores muito próximos (Tabela 2). Teoricamente, os valores deveriam ser iguais, porém, nossa análise sugere que esta pequena variação se deve principalmente à diferença entre as resoluções espaciais das imagens utilizadas e pela pequena, mas crucial, diferença das regiões espectrais das bandas envolvidas nas análises, principalmente a banda Verde (Tabela 1).

Analisando as classes quanto à representatividade espacial, em ambas as imagens, a menos representada foi a classe envolvendo os corpos d'água, seguida da classe de vegetação preservada e vegetação de áreas úmidas. A classe de vegetação antropizada/solo exposto foi a classe mais representada em ambas as classificações.

Porém fazendo uma análise dos dados em termos das características dos polígonos gerados pela classificação supervisionada por máxima verossimilhança de ambas as imagens, pode-se notar que os polígonos gerados pela classificação da imagem ALOS AVNIR-2 apresentam-se em número superior a da imagem LANDSAT 5 TM e possuem dimensões mais reduzidas e variadas em termos de área. Fato este associado a sua maior resolução espacial.

Outro fato importante é o padrão visto em todas as classes analisadas é que a representatividade das áreas em termos de número de polígonos gerados segue o padrão de que quanto menor a área dos mesmos maior o número de polígonos gerados, havendo um decréscimo em termos numéricos a medida que a área dos polígonos envolvidos aumenta. Exceções ocorreram, como alguns aumentos numéricos em determinado intervalo de área para algumas classes.

Quanto a classificação supervisionada por Máxima Verossimilhança, a técnica aplicada neste trabalho apresentou resultados condizentes quando comparados visualmente com a composição colorida das respectivas imagens (Figura 5). 
Com resultados muito semelhantes quanto aos resultados em termos de áreas calculadas, sugere-se como uma melhor opção a adoção das imagens LANDSAT 5 TM. Primeiramente por sua ampla utilização em estudos de uso do solo e de vegetação na Amazônia o que tornam suas características muito bem conhecida pela comunidade de usuários. Em segundo lugar pela ótima relação custo/benefício devido ser disponibilizada gratuitamente e com isso facilitando o acesso por projetos sem patrocínio ou verba. A imagem ALOS AVNIR-2 apresenta resultados similares e tem a vantagem de possuir uma resolução espacial superior a da LANDSAT 5 TM o que pode ser um diferencial caso o projeto possua recursos para aquisição das imagens.

Analisando a área de trabalho, observou-se que na região há a predominância de áreas utilizadas em diversas atividades antrópicas e escassez de áreas com vegetação preservada. Esse fato é diametralmente oposto ao que se esperaria de uma área situada na Amazônia Legal, onde, pela legislação vigente deveria apresentar $80 \%$ de seu território com vegetação preservada. Os resultado do presente estudo corrobora com os estudos feitos na região e adjacências que indicam que mesmo estando dentro da área considerada como Amazônia Legal, o desmatamento da vegetação está bem acima do que é permitido pela Lei $n^{0}$ 12.651, de 25 de Maio de 2012 que dispõe sobre a proteção da vegetação nativa, assim é importante que fiscalização, planos de manejo e recuperação florestal sejam estimulados na região para quem sabe no futuro a região possa vir a se recuperar.

\section{REFERÊNCIAS}

ALMEIDA, C.A.; VALERIANO, D.M.; ESCADA, M.I.S. e RENNÓ, C.D. Estimativa de área de vegetação secundária na Amazônia Legal Brasileira. Acta Amazônica, Vol. 40, n. 2 2010: 289-302.

ALVES, D.S.A.; MOREIRA, J.C.; KALIL, E.M.; SOARES, J.V.; FERNANDEZ, O.; ALMEIDA, S.; ORTIZ, J.D. e AMARAL, S. Mapeamento do Uso da Terra em Rondônia Utilizando Técnicas de Segmentação e Classificação de Imagens TM. Anais VIII Simpósio Brasileiro de Sensoriamento Remoto, Salvador, Brasil, 14-19 abril 1996, INPE, p. 71-79.

BOULOGNE, M. 2011. Apport dês satellites Landsat et Spot sur la petite agriculture familial a Carlinda, Mato Grosso (Brésil). Dissertação de Mestrado, Département de Géographie et aménagement de l'espace, Université Rennes 2, 56 p.

CASTRO, S.P.; BARROZO, J.C.; COVEZZI, M.; PRETI O. A colonização oficial no Mato Grosso: a nata e a borra da sociedade, Cuiabá: ed. UFMT/NERU, 2002. 236 p. 
CORREIA, A. H.; FORMAGGIO, A. R.; SHIMABUKURO, Y. E. e DUARTE, V. Utilização de dados de reflectância MODIS (composições de 8 dias) para detecção de desmatamentos na Amazônia. Anais XII Simpósio Brasileiro de Sensoriamento Remoto, Goiânia, Brasil, 16-21 abril 2005, INPE, p. 481-488.

FEARNSIDE, P. M. Soybean cultivation as a threat to the environment in Brazil. Environmental Conservation, n.28, p.2338,2001

FERREIRA, G.F.; FERREIRA, N.C. E.; FERREIRA, M.F. 2008. Sensoriamento remoto da vegetação: evolução e estadoda-arte. Acta Sci. Biol. Sci. Maringá, v. 30, n. 4, p. 379-390, 2008.

FERREIRA, A. L. J.; SOUSA, G. G.; PASsOS, J. S.; BALDINI, L. M. e SANTOS NETO, P. M. Análise da Evolução do Desmatamento no Município de Carlinda-MT nos Anos de 1980, 1990 e 2011. 14 EGAL Encuentro de Geógrafos de América Latina, Peru 2013.

IBGE (Instituto Brasileiro de Geografia e Estatística). CIDADES. informações sobre os municípios brasileiros. 2010. Disponível em: http://cod.ibge.gov.br/43F7 Acesso em: Agosto 2014.

INPE (Instituto Nacional de Pesquisas Espaciais, Brazil), Projeto PRODES. 2008. Disponível em : <http://www.obt.inpe.br/prodes/prodes_1988_2007.htm> Acesso em: Agosto 2014.

PONZONI, F. J. e REZENDE, A. C. P. Caracterização espectral de estágios sucessionais de vegetação arbórea secundária arbórea em Altamira (PA), através de dados orbitais. Revista Árvore, v.28, n.4, p.535-545, 2004.

ROSA, R. Introdução ao sensoriamento remoto. Uberlândia: EDUFU, 2003. 228p.

SÁ, I. I. S.; GALVÍNCIO, J. D.; MOURA, M. S. B. e SÁ I. B. Uso do índice de vegeteção da diferença normalizada (IVDN) para a daracterização da cobertura vegetal da região do Araripe Pernambuco. RBGF - Revista Brasileira de Geografia Física. Recife-PE Vol. 01 n.01 Mai/Ago 2008, 28-38.

SKOLE, D.L.; CHOMENTOWSKI, W.H.; SALAS e W.A. e NOBRE, A.D., 1994, Physical and Human Dimensions of Deforestation in Amazonia. Bioscience, 44, 314-322.

SOUZA, G.M. e MATRICARDI, E. A. T. Mapeamento do uso e ocupação do solo nos anos 2000, 2005 e 2010 no município de Arraias, bacia do rio Paranã, Tocantins, Brasil, com dados de sensoriamento remoto. Anais XV Simpósio Brasileiro de Sensoriamento Remoto - SBSR, Curitiba, PR, Brasil, 30 de abril a 05 de maio de 2011, INPE p.6450 